CARVALHO, ADF; NOGUEIRA, MTM; SILVA, GO; LUZ, JMQ; MACIEL, GM; RABELO, PG. 2017. Seleção de genótipos de cenoura para caracteres fenotípicos de raiz. Horticultura Brasileira 35: 097-102. DOI - http://dx.doi.org/10.1590/S0102-053620170115

\title{
Seleção de genótipos de cenoura para caracteres fenotípicos de raiz
}

\section{Agnaldo DF Carvalho'; Marco TM Nogueira²; Giovani O Silva³; José MQ Luz²; Gabriel M Maciel; Paulo G Rabelo 5}

${ }^{1}$ Embrapa Hortaliças, Brasília-DF, Brasil; agnaldo.carvalho@embrapa.br; ${ }^{2}$ Universidade Federal de Uberlandia (UFU), Uberlândia-MG, Brasil; marcotulio_mn@hotmail.com; jmagno@umuarama.ufu.br (autor correspondente); ${ }^{3}$ Embrapa Hortaliças/SPM, Canoinhas-SC, Brasil;. giovani.olegario@embrapa.br; ${ }^{4}$ Universidade Federal de Uberlandia (UFU), Monte Carmelo-MG, Brasil; gabrielmaciel@iciag. ufu.br; ${ }^{5}$ Centro Universitário do Cerrado (UNICERP), Patrocínio-MG, Brasil; rabelopg@hotmail.com

\section{RESUMO}

O objetivo desse trabalho foi verificar a eficiência da seleção de genótipos de cenoura para caracteres fenotípicos de raiz. Foi avaliado um conjunto de onze genótipos, sendo quatro populações em fase de melhoramento $(09 ; 14 ; 16$ e 17), uma cultivar (BRS Planalto), cinco híbridos experimentais $(17 ; 20 ; 03 ; 27$ e 31$)$ e um híbrido comercial (Juliana), para caracteres fenotípicos de raiz. O experimento foi realizado em Uberlândia-MG, no cultivo de verão do ano de 2014, com plantio no dia 30 de janeiro e colheita realizada 113 dias após. O delineamento experimental utilizado foi blocos casualizados com quatro repetições. Foram estimados os valores genotípicos; os ganhos com a seleção; os efeitos da seleção direta nos demais caracteres; e ganhos pelo índice de seleção da distância ao ideótipo. Foi verificado que a seleção simultânea para os caracteres massa total de raízes, massa de raízes comerciais, diâmetro de raízes, maior porcentagem de raízes com formato cilíndrico, maior porcentagem de raízes sem ombro verde e maior porcentagem de raízes com coloração alaranjada escura possibilita ganhos positivos para todos os caracteres. A seleção direta possibilita ganhos maiores para cada caráter, porém para os caracteres massa total de raiz, porcentagem de raízes com formato cilíndrico, porcentagem de raízes sem ombro verde e porcentagem de raízes com coloração alaranjada escura, ocasionaria a redução nos ganhos para outros caracteres. No conjunto dos caracteres avaliados os melhores genótipos foram as populações 14, 16 e 17.

Palavras-chave: Daucus carota, seleção, qualidade de raiz, rendimento de raiz.

\section{ABSTRACT \\ Selection of carrot genotypes for phenotypic root characters}

We studied the efficiency of selecting carrot genotypes based on phenotypic root characters. Eleven genotypes were evaluated, which included four breeding populations $(09 ; 14 ; 16$ and 17), one openpollinated cultivar (BRS Planalto), five experimental hybrids (17; 20; 03; 27 and 31) and a commercial hybrid (Juliana). The experiment was carried out during the summer crop of 2014 (sown January $30^{\text {th }}$ and harvested after 113 days) in Uberlandia, Minas Gerais State, Brazil. A randomized block design with four replications was used. We estimated genotypic values, direct gains, the effect of direct selection on other characters, and gains related to the selection index of the distance to the biotype. We determined that the simultaneous selection of total root mass, commercially-viable root mass, root diameter, high percentage of cylindrical roots, high percentage of roots without green shoulders and high percentage of dark-orange roots led to positive gains in all characters. Direct selection produced the greatest gains in each character; however, total root mass, percentage of cylindrical roots, percentage of roots without green shoulders and percentage of dark-orange roots led to lower gains in other characters. The best genotypes considering all characters were populations 14, 16 and 17.

Keywords: Daucus carota, selection, root quality, root yield.

\section{(Recebido para publicação em 27 de outubro de 2015; aceito em 11 de agosto de 2016) (Received on October 27, 2015; accepted on August 11, 2016)}

\begin{abstract}
$\mathrm{A}$ cenoura é uma das hortaliças mais importantes em produção e consumo no Brasil. Segundo dados do IBGE são cultivados mais de 26 mil ha o que rende uma produção de aproximadamente 780 mil ton. por ano (Anuário Brasileiro de Hortaliças, 2014).

O padrão comercial de raízes deve possuir, preferencialmente, comprimento variando de 16 a $22 \mathrm{~cm}$, diâmetro aproximado de $3 \mathrm{~cm}$, formato cilíndrico, ausência de pigmento roxo ou verde
\end{abstract}

na parte superior da raiz (ombro roxo/ verde) coloração alaranjada entre outras. Genótipos que possuem coloração interna das raízes distribuída uniformemente entre xilema e floema são preferidos, pois proporcionam bom aspecto visual.

As inferências sobre os materiais genéticos em experimentos de campo, a fim de se classificar aqueles candidatos a serem lançados como cultivares comerciais, devem ser baseadas nos verdadeiros valores genotípicos, ou seja, em médias genotípicas e não fenotípicas. As médias genotípicas são as médias futuras, quando as cultivares forem plantadas em cultivos comerciais. Já que esta predição necessita dos verdadeiros valores dos componentes de variância, torna-se importante o uso dos métodos da melhor predição linear não viciada (BLUP) e da máxima verossimilhança restrita (REML). Para isso, a consideração de efeitos de tratamentos como aleatórios é essencial, pois só assim pode-se 
fazer seleção genética, caso contrário, a seleção é fenotípica. Porém, em plantas anuais ainda são incipientes as literaturas usando essa teoria, especialmente no Brasil (Borges et al., 2010).

Segundo Bolker et al. (2009), é importante escolher uma estatística adequada para testar os efeitos dos modelos mistos. No caso da análise de deviance (Anadev), é possível testar os efeitos fixos e aleatórios dos modelos. Para os efeitos aleatórios utilizando o programa estatístico Selegen (Resende, 2002b) são obtidas as deviances dos logaritmos do ponto de máxima da função de verossimilhança residual, e pelas diferenças entre as deviances obtidas a razão de verossimilhança (LR) (Resende, 2002a). Bolker et al. (2009) citam como vantagem da análise de deviance a penalização automática de modelos complexos evitando assim, o excesso de encaixes e como desvantagem a amostragem de Monte Carlo via Cadeias de Markov. No entanto, no caso do Selegen a significância da LR é testada usando o teste qui-quadrado com 1 grau de liberdade (Resende, 2002b). Em relação à seleção de genótipos superiores para múltiplos caracteres, o processo de seleção pode ser mais eficiente com a utilização de índices de seleção, que permitem combinar as múltiplas informações contidas na unidade experimental, de modo que seja possível a seleção com base em um complexo de variáveis que reúna vários atributos de interesse (Cruz et al., 2012).

Várias metodologias de índices de seleção têm sido descritas, algumas são baseadas no estabelecimento de pesos econômicos ou de ganhos desejados para os caracteres. No entanto, outros métodos como a menor distância em relação ao genótipo ideal ou ideótipo (Cruz et al., 2012) é uma alternativa às metodologias que necessitam da determinação dos pesos econômicos ou ganhos desejados.

Dessa forma, o objetivo do trabalho foi verificar a eficiência da seleção de genótipos de cenoura para caracteres fenotípicos de raiz.

\section{MATERIAL E MÉTODOS}

O experimento foi realizado em
Uberlândia-MG, no cultivo de verão do ano de 2014, com plantio no dia 30 de janeiro e colheita realizada 113 dias após.

Foi avaliado um conjunto de onze genótipos, sendo quatro populações em fase de melhoramento $(09 ; 14 ; 16$ e 17), uma população comercial (BRS Planalto), cinco híbridos experimentais $(17 ; 20 ; 03 ; 27$ e 31$)$ e um híbrido comercial (Juliana).

Utilizou-se o delineamento experimental de blocos casualizados com quatro repetições e as parcelas foram constituídas de quatro linhas de plantio com comprimento de 2 metros, espaçadas em $25 \mathrm{~cm}$. A área útil da parcela foi constituída das duas linhas centrais, excluindo-se as duas linhas da extremidade e $25 \mathrm{~cm}$ no início e final das duas linhas centrais. A adubação foi realizada no plantio com $200 \mathrm{~g}$ de adubo comercial NPK (04-14-08) por metro linear de canteiro e aos 33 dias após o plantio foi realizado o desbaste seguido de adubação com $80 \mathrm{~g}$ por metro linear de canteiro com sulfato de amônio. Durante o desbaste padronizou-se o espaçamento de 2,5 cm entre as plantas dentro da linha em todo experimento. Os tratos culturais e fitossanitários foram realizados conforme preconizado para a cultura da cenoura (Filgueira, 2008).

Aos 113 dias após o plantio, as raízes de cada parcela útil foram colhidas. Em seguida, realizou-se as avaliações para os caracteres: massa total de raízes $(\mathrm{kg})$; massa de raízes comerciais (10 a $26 \mathrm{~cm}$ de comprimento). Em uma amostra ao acaso de 10 raízes foi determinado o diâmetro médio de raízes $(\mathrm{cm})$, realizado na porção média da raiz, utilizando um paquímetro; porcentagem de raízes com formato cilíndrico; porcentagem de raízes sem ombro verde; porcentagem de raízes com coloração alaranjada escura. Os dados de massa de raízes foram transformados para t/ha.

Os dados de cada caráter foram submetidos à análise de deviance, para estimar os parâmetros genéticos, os valores genotípicos (média fenotípica corrigida pelos valores genéticos) e os intervalos de confiança dos valores genotípicos, por meio da metodologia Reml/Blup para verificar a confiabilidade dos resultados (Resende, 2002b). Para a análise de deviance utilizou-se o modelo: $y=X r$
$+Z g+e$, em que $y$ é o vetor de dados fenotípicos observados; $r$ é o vetor de efeitos de repetições (assumidos como fixos); $g$ é o vetor dos efeitos genotípicos (assumidos como aleatórios); $e$, o vetor de erros (aleatórios), e $X$ e $Z$, matrizes de incidência para os referidos efeitos (Resende, 2002a).

As equações de modelos mistos para a predição de $\mathrm{r}$ e $\mathrm{g}$ equivalem a:

$$
\left[\begin{array}{cc}
X^{\prime} X & X^{\prime} Z \\
Z^{\prime} X & Z^{\prime} Z
\end{array}\right]\left[\begin{array}{l}
r \\
g
\end{array}\right]=\left[\begin{array}{c}
X^{\prime} y \\
Z^{\prime} y
\end{array}\right]
$$

Como o número de genótipos avaliados foi superior a dez, os efeitos de genótipos foram considerados como aleatórios (Resende \& Duarte, 2007). Para a realização destas análises foi utilizado o aplicativo computacional Selegen (Resende, 2002b).

Foram estimados os ganhos diretos por meio da seleção (GS) dos três melhores genótipos, substituindo a matriz de médias pelos valores genotípicos e usando a fórmula GS $=\mathrm{Ds} \times \mathrm{h}^{2}$, em que Ds corresponde ao diferencial de seleção, ou diferença entre os valores genotípicos dos genótipos selecionados subtraída do valor genotípico médio e $\mathrm{a} \mathrm{h}^{2}$ é a estimativa da herdabilidade no sentido amplo; e também os ganhos que a seleção dos melhores genótipos para cada caráter principal ocasionariam nos demais caracteres, com a mesma fórmula descrita acima. Também foram estimados os ganhos com a seleção pelo índice de seleção da menor distância ao ideótipo (Cruz et al., 2012), sendo que o ideótipo seria aquele genótipo com os valores genotípicos máximos verificados para cada caráter. Estas análises foram realizadas utilizando-se o aplicativo computacional Genes (Cruz, 2006).

\section{RESULTADOS E DISCUSSÃO}

A análise de deviance revelou diferenças significativas entre os genótipos para todos os caracteres avaliados (Tabela 1). O coeficiente de variação (CV) fenotípico foi menor para o caráter diâmetro de raiz, 7,68\%, e foi maior para os caracteres porcentagem de ombro verde $(35,89 \%)$ e porcentagem de raízes com coloração alaranjada escura $(22,04 \%)$. O CV para os demais caracteres variou de 10,14 a 17,23\% (Tabela 1). 
Considerando-se que o rendimento de raízes é um caráter quantitativo, que normalmente sofre grande influência ambiental, verifica-se que este expe- rimento teve adequada precisão experimental. O caráter ombro verde é, segundo Silva et al. (2013), um caráter fortemente influenciado pelo ambiente, e de difícil seleção, o que explicaria o maior valor do coeficiente de variação. Silva \& Vieira (2008) verificaram valor do CV para este caráter semelhante a

Tabela 1. Valores da estatística do teste razão de verossimilhança (LRT) da análise de deviance e parâmetros genéticos, da avaliação de 11 genótipos de cenoura \{values of the statistical likelihood ratio test (LRT) of deviance analysis and genetic parameters, evaluating 11 carrot genotypes\}. Uberlândia, UFU, 2015.

\begin{tabular}{lcccccc}
\hline Caráter & $\begin{array}{c}\text { Massa } \\
\text { total } \\
\mathbf{( t / h a )}\end{array}$ & $\begin{array}{c}\text { Massa } \\
\text { comercial } \\
\mathbf{( t / h a )}\end{array}$ & $\begin{array}{c}\text { Diâmetro } \\
\text { raiz (cm) }\end{array}$ & $\begin{array}{c}\text { Raízes de } \\
\text { formato } \\
\text { cilíndrico (\%) }\end{array}$ & $\begin{array}{c}\text { Raízes sem } \\
\text { ombro } \\
\text { verde (\%) }\end{array}$ & $\begin{array}{c}\text { Raízes com } \\
\text { coloração laranja } \\
\text { escura (\%) }\end{array}$ \\
\hline Genótipo $^{1}$ & $20,15^{* *}$ & $8,12^{* *}$ & $10,31^{* *}$ & $13,12^{* *}$ & $10,63^{* *}$ & $5,92^{*}$ \\
Herdabilidade média dos genótipos & 0,88 & 0,74 & 0,78 & 0,82 & 0,78 & 0,69 \\
Acurácia na seleção & 0,94 & 0,86 & 0,88 & 0,9 & 0,89 & 0,83 \\
CV (\%) fenotípico & 10,14 & 14,17 & 7,68 & 17,23 & 35,89 & 22,04 \\
Média fenotípica geral & 71,07 & 38,37 & 2,73 & 59,32 & 34,77 & 60,45 \\
\hline
\end{tabular}

${ }^{1}$ Valores de LRT; Significativo a $* \mathrm{p}=0,05, * * \mathrm{p}=0,01$ pelo teste $\mathrm{x}^{2}$ com 1 grau de liberdade (LRT values; $*$ Significant at $\mathrm{p}=0.05, * * \mathrm{p}=0.01$ by $\mathrm{x}^{2}$ test with 1 degree of freedom).

Tabela 2. Valores genotípicos preditos $(\mathrm{u}+\mathrm{g})$ e seus limites inferior (LIIC) e superior (LSIC) dos intervalos de confiança, da avaliação de 11 genótipos de cenoura \{predicted genotypic values $(\mathrm{u}+\mathrm{g})$ and their lower limits (LIIC) and higher limits (LSIC) of confidence intervals, 11 genotypes of carrot being evaluated\}. Uberlândia, UFU, 2015.

\begin{tabular}{|c|c|c|c|c|c|c|c|c|c|}
\hline \multirow{2}{*}{ Genótipo } & \multicolumn{3}{|c|}{ Massa total (t/ha) } & \multicolumn{3}{|c|}{ Massa comercial (t/ha) } & \multicolumn{3}{|c|}{ Diâmetro raiz (cm)] } \\
\hline & LIIC & $\mathbf{u}+\mathbf{g}$ & LSIC & LIIC & $\mathbf{u}+\mathbf{g}$ & LSIC & LIIC & $\mathbf{u}+\mathbf{g}$ & LSIC \\
\hline População 09 & 60,31 & 68,83 & 77,35 & 25,53 & 30,69 & 35,84 & 2,44 & 2,65 & 2,86 \\
\hline População 14 & 67,03 & 75,54 & 84,06 & 36,26 & 41,41 & 46,57 & 2,95 & 3,16 & 3,37 \\
\hline População 16 & 67,80 & 76,32 & 84,84 & 37,24 & 42,40 & 47,55 & 2,64 & 2,85 & 3,06 \\
\hline População 17 & 70,35 & 78,87 & 87,39 & 36,64 & 41,79 & 46,95 & 2,68 & 2,89 & 3,10 \\
\hline BRS Planalto & 68,76 & 77,28 & 85,80 & 36,04 & 41,20 & 46,35 & 2,46 & 2,67 & 2,88 \\
\hline Híbrido 17 & 68,56 & 77,08 & 85,60 & 34,98 & 40,14 & 45,29 & 2,49 & 2,70 & 2,91 \\
\hline Híbrido 20 & 54,47 & 62,99 & 71,51 & 34,61 & 39,77 & 44,92 & 2,45 & 2,66 & 2,87 \\
\hline Híbrido 23 & 61,61 & 70,13 & 78,65 & 27,78 & 32,94 & 38,09 & 2,37 & 2,57 & 2,78 \\
\hline Híbrido 27 & 63,18 & 71,70 & 80,22 & 34,60 & 39,75 & 44,91 & 2,49 & 2,70 & 2,91 \\
\hline Híbrido 31 & 66,91 & 75,43 & 83,95 & 32,55 & 37,70 & 42,86 & 2,47 & 2,68 & 2,89 \\
\hline \multirow[t]{2}{*}{ Juliana } & 39,13 & 47,65 & 56,17 & 29,15 & 34,30 & 39,46 & 2,32 & 2,53 & 2,73 \\
\hline & \multicolumn{3}{|c|}{$\begin{array}{c}\text { Raízes de formato cilíndrico } \\
(\%)\end{array}$} & \multicolumn{3}{|c|}{$\begin{array}{c}\text { Raízes sem ombro verde } \\
(\%)\end{array}$} & \multicolumn{3}{|c|}{$\begin{array}{c}\text { Raízes com coloração laranja } \\
\text { escuro }(\%)\end{array}$} \\
\hline População 09 & 49,11 & 59,88 & 70,64 & 26,36 & 38,88 & 51,40 & 63,75 & 75,62 & 87,49 \\
\hline População 14 & 40,93 & 51,69 & 62,45 & 26,36 & 38,88 & 51,40 & 58,59 & 70,46 & 82,33 \\
\hline População 16 & 49,11 & 59,88 & 70,64 & 22,43 & 34,95 & 47,47 & 56,87 & 68,74 & 80,61 \\
\hline População 17 & 61,39 & 72,15 & 82,91 & 36,18 & 48,70 & 61,22 & 49,99 & 61,86 & 73,73 \\
\hline BRS Planalto & 47,07 & 57,83 & 68,59 & 10,64 & 23,16 & 35,68 & 41,39 & 53,26 & 65,13 \\
\hline Híbrido 17 & 63,44 & 74,20 & 84,96 & 14,57 & 27,09 & 39,61 & 44,83 & 56,70 & 68,57 \\
\hline Híbrido 20 & 40,93 & 51,69 & 62,45 & 14,57 & 27,09 & 39,61 & 44,83 & 56,70 & 68,57 \\
\hline Híbrido 23 & 45,02 & 55,78 & 66,55 & 10,64 & 23,16 & 35,68 & 39,67 & 51,54 & 63,41 \\
\hline Híbrido 27 & 61,39 & 72,15 & 82,91 & 16,54 & 29,06 & 41,58 & 37,96 & 49,82 & 61,69 \\
\hline Híbrido 31 & 42,98 & 53,74 & 64,50 & 22,43 & 34,95 & 47,47 & 48,27 & 60,14 & 72,01 \\
\hline Juliana & 32,75 & 43,51 & 54,27 & 44,04 & 56,56 & 69,08 & 48,27 & 60,14 & 72,01 \\
\hline
\end{tabular}


este trabalho, $30,74 \%$.

Os elevados valores da acurácia na seleção, que superou $80 \%$ para todos os caracteres e da herdabilidade média dos clones, ou herdabilidade para a média genotípica, que foi superior ao valor de $70 \%$ para quase todos os caracteres, com exceção para o caráter porcentagem de raízes com coloração alaranjada escura, que foi de 69\% (Tabela 1) indica que elevado progresso genético com a seleção pode ser obtido para a maioria dos caracteres (Tabela 1). Segundo Resende (2002a), o valor da acurácia da seleção, que é a raiz quadrada da herdabilidade média dos clones, evidencia alta precisão nas inferências dos valores genotípicos, indicando que a condução experimental foi apropriada para a caracterização dos genótipos superiores (Ramalho et al., 2011).

Os valores das médias fenotípicas para os caracteres de rendimento foram de $71,07 \mathrm{t} /$ ha e $38,37 \mathrm{t} /$ ha para massa total de raízes e massa de raízes comerciais, respectivamente (Tabela 1). Estes rendimentos podem ser considerados elevados, indicando que as condições experimentais proporcionaram aos genótipos adequada expressão do seu potencial produtivo. Estes valores estão bem acima da produtividade média nacional que é de 31,2 t/ha (Embrapa Hortaliças, 2012).

$\mathrm{Na}$ observação dos valores genotípicos (Tabela 2), que se referem aos valores das médias fenotípicas corrigidas pelos valores genéticos correspondentes ao desempenho previsto dos genótipos quando estes forem cultivados, verificou-se que para o caráter massa total de raízes, a maioria dos genótipos agruparam conjuntamente nos limites do intervalo de confiança do genótipo primeiro classificado, que foi a população 17 , com rendimentos variando de 70,34 a 87,39 t/ha, com exceção do híbrido comercial Juliana, que apresentou rendimento total menor do que os demais. Para o caráter massa de raízes comerciais o genótipo com maior rendimento foi a população 16 , com rendimentos variando de 37,24 a 47,55 t/ha, porém a maioria dos genótipos pertenceu ao mesmo intervalo de confiança, com exceção da população
09, que apresentou a menor massa de raízes comerciais.

O genótipo com maior diâmetro de raiz foi a população 14 , com valores variando de 2,95 a $3,36 \mathrm{~cm}$, sendo que as populações 17 e 16 pertenceram ao mesmo intervalo de confiança do primeiro colocado, e, portanto, foram os genótipos com as raízes mais grossas. No entanto estas duas últimas populações não diferiram estatisticamente dos demais genótipos avaliados.

O híbrido 17 apresentou a maior porcentagem de raízes com formato cilíndrico, variando de 63,43 a 84,95\%; a maioria dos demais genótipos pertenceu ao mesmo intervalo de confiança, com exceção da população 14, do híbrido 20 e do híbrido Juliana, que apresentaram menor proporção de raízes com formato cilíndrico que o híbrido 17.

O híbrido Juliana se destacou positivamente por apresentar a maior porcentagem de raízes sem a presença de ombro verde. Para este híbrido os valores foram de 44,04 a 69,08\%. Cinco genótipos pertenceram ao mesmo intervalo de confiança observado para

Tabela 3. Ganhos diretos (diagonal em negrito) e ganhos que a seleção dos melhores genótipos para cada caráter principal nas linhas ocasionariam nos demais caracteres das colunas, e pelo índice de seleção da distância ao ideótipo, e genótipos selecionados por estas metodologias, da avaliação de 11 genótipos de cenoura \{direct gains (diagonal in bold) and gains that the selection of the best genotypes for each major character lines would result in the other characters of the columns, and the selection index of distance to ideotype and genotypes selected by these methods, 11 carrot genotypes being evaluated\}. Uberlândia, UFU, 2015.

\begin{tabular}{lcccccc}
\hline Caráter & $\begin{array}{c}\text { Massa total } \\
\text { (t/ha) }\end{array}$ & $\begin{array}{c}\text { Massa } \\
\text { comercial } \\
\text { (t/ha) }\end{array}$ & $\begin{array}{c}\text { Diâmetro } \\
\text { raiz (cm) }\end{array}$ & $\begin{array}{c}\text { Raízes de } \\
\text { formato } \\
\text { cilíndrico (\%) }\end{array}$ & $\begin{array}{c}\text { Raízes sem } \\
\text { ombro verde coloração laranja } \\
\text { (\%) }\end{array}$ & $\begin{array}{c}\text { Raízes com } \\
\text { escuro (\%) }\end{array}$ \\
\hline Massa total & $\mathbf{8 , 2 4}$ & 5,17 & 0,59 & 12,06 & $-4,04$ & $-3,62$ \\
Massa comercial & 7,21 & $\mathbf{6 , 7 6}$ & 6,69 & 2,65 & 13,72 & 7,47 \\
Diâmetro raiz & 9,54 & 10,18 & $\mathbf{7 , 8 2}$ & 2,83 & 10,01 & 12,47 \\
Raízes de formato cilíndrico & 5,94 & 4,23 & 0,87 & $\mathbf{1 8 , 6 4}$ & 0,40 & $-4,92$ \\
Raízes sem ombro verde & $-7,36$ & $-5,37$ & $-1,22$ & $-1,11$ & $\mathbf{3 0 , 0 0}$ & 6,17 \\
Raízes com coloração laranja & 3,07 & $-0,40$ & 4,40 & $-2,99$ & 6,33 & $\mathbf{1 2 , 6 9}$ \\
escuro & & & & & & \\
\hline
\end{tabular}

Genótipos selecionados pelo ganho direto

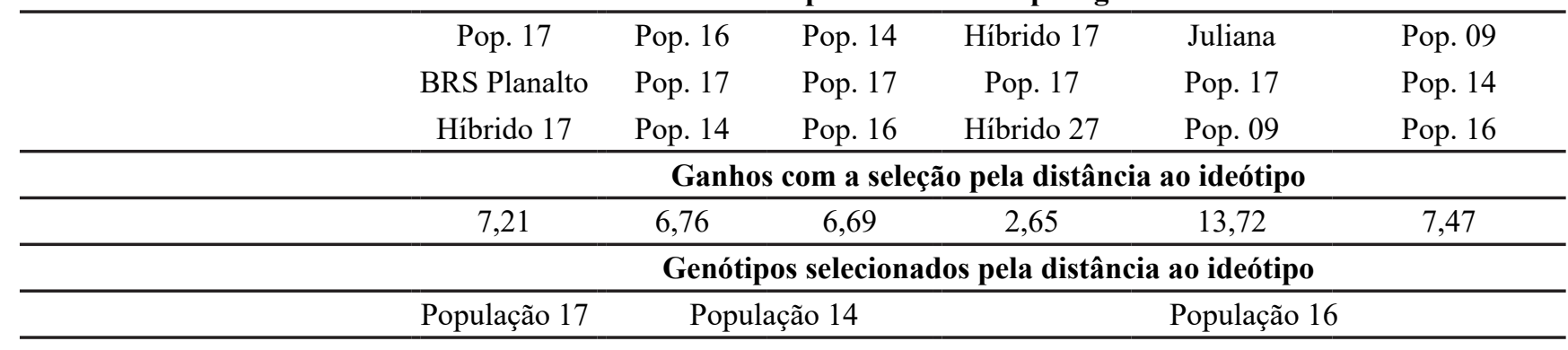


Juliana: populações $09,14,16,17$ e o híbrido 31 .

A população 09 apresentou a maior porcentagem de raízes com coloração alaranjada escura, com valores de 63,75 a $87,49 \%$. No entanto, a grande maioria dos genótipos pertenceu aos limites do intervalo de confiança observado para esta população, com exceção do híbrido 27 que apresentou os menores valores para esta característica, 37,95 a 61,69\%.

Os ganhos diretos estimados com a seleção dos três melhores genótipos para cada caráter (maiores valores genotípicos), em relação ao valor médio de todos os genótipos, estão destacados em negrito, na diagonal da Tabela 3. São esperados ganhos maiores para os caracteres porcentagem de raízes sem ombro verde $(30 \%)$, porcentagem de raízes com formato cilíndrico $(18,64 \%)$ e porcentagem de raízes com coloração alaranjada escura $(12,69 \%)$.

No entanto, foi observado pelos valores dos ganhos que a seleção dos melhores genótipos para cada caráter principal (seleção direta) ocasionaria nos demais caracteres (Tabela 3); que a seleção para maior massa total de raízes ocasionaria diminuição na porcentagem de raízes sem ombro verde e com coloração alaranjada escura, com ganhos estimados de $-4,04$ e $-3,62 \%$, respectivamente. A seleção para maior massa de raízes comerciais e diâmetro de raízes ocasionaria ganhos positivos para todos os caracteres. Em contrapartida, vale ressaltar que raízes com maior diâmetro foram associadas à menor intensidade da cor, especialmente na região do xilema (Silva \& Vieira, 2008, Silva et al., 2012). Alves et al. (2006) identificaram que o caráter diâmetro de raiz apresenta alto valor de correlação com rendimento de raízes. Tais caracteres são considerados fu0ndamentais em programas de melhoramento genético de cenoura visando produtividade (McCollum, 1971; Vieira et al., 2001; Singh et al., 2002). Estes resultados corroboram com o presente estudo e são de certa maneira esperados, pois massa de raízes é uma característica dependente do diâmetro das raízes.

A seleção para maior porcentagem de raízes com formato cilíndrico e com coloração alaranjado forte ocasionaria ganhos negativos em cada um destes caracteres. E a seleção direta para menor porcentagem de raízes sem ombro verde ocasionaria ganhos negativos para a maioria dos caracteres, com exceção de porcentagem de raízes com coloração alaranjado escura. Silva \& Vieira (2008) também verificaram menor expressão de ombro verde em raízes com coloração mais escura, e associações significativas entre maior ombro verde e maior rendimento e diâmetro de raiz. Estas relações com ombro verde e coloração de raiz provavelmente ocorrem, pois a seleção é realizada concomitantemente para estas características, enquanto que raízes maiores proporcionam melhor visualização desta característica. Pode-se verificar que, com exceção da massa de raízes comerciais e do diâmetro da raiz (Tabela 3), não houve coincidência dos melhores genótipos para todas as características de interesse, o que também foi observado pela classificação dos valores genotípicos mostrada na Tabela 2. Considerando todos os caracteres conjuntamente, com a utilização do índice de seleção da menor distância ao ideótipo, verifica-se que se destacaram as populações 14,16 e 17 . O ganho com a seleção por esta estratégia seria menor do que a seleção para cada caráter, mas foi positiva para todas as características, indicando situação favorável para o melhoramento.

A busca por variedades comerciais que combinem todas estas características é um grande desafio em programas de melhoramento genético de cenoura, pois além de produtivas, deve-se buscar outras características de interesse fundamentais para que o produtor consiga aceitação do produto no mercado consumidor.

A seleção conjunta para os caracteres massa total de raízes, massa de raízes comerciais, diâmetro de raízes, maior porcentagem de raízes com formato cilíndrico, maior porcentagem de raízes sem ombro verde e maior porcentagem de raízes com coloração alaranjado escura possibilita ganhos positivos para todos os caracteres. A seleção direta possibilita ganhos maiores para cada caráter, porém para os caracteres massa total de raiz, porcentagem de raízes com formato cilíndrico, porcentagem de raízes sem ombro verde e porcentagem de raízes com coloração alaranjada escura, ocasionaria a redução nos ganhos para outros caracteres, sendo que, no conjunto dos caracteres avaliados, os melhores genótipos são as populações 17, 14 e 16, estando essa última, em tramitação para envio para registro como cultivar junto ao Ministério da Agricultura Pecuária e Abastecimento.

\section{REFERÊNCIAS}

ALVES, JCS; PEIXOTO, JR; VIEIRA, JV; BOITEUX, LS. 2006. Herdabilidade e correlações genotípicas entre caracteres de folhagem e sistema radicular em famílias de cenoura, cultivar Brasília. Horticultura Brasileira 24: 363-367.

ANUÁRIO BRASILEIRO DE HORTALIÇAS. 2014. Brazilian Vegetable Yearbook. Santa Cruz do Sul: Gazeta. 90p.

BOLKER, BM; BROOKS, ME; CLARK, CJ; GEANGE, SW; POULSEN, JR; STEVENS, MHH; WHITE, JSS. 2009. Generalized linear mixed models: a practical guide for ecology and evolution. Trends in Ecology \& Evolution 24: 127-135.

BORGES, V; FERREIRA, PV; SOARES, L; SANTOS, GM; SANTOS, AMM. 2010. Seleção de clones de batata-doce pelo procedimento REML/BLUP. Acta Scientiarum Agronomy 32: 643-649.

CRUZ, CD. 2006. Programa Genes - Biometria. Viçosa: UFV. 382p.

CRUZ, CD; REGAZZI, AJ; CARNEIRO, PC. 2012. Métodos biométricos aplicados ao melhoramento genético. Viçosa: UFV, 4 ed. $414 \mathrm{p}$.

EMBRAPA HORTALIÇAS. 2012. Situação da Produção de Hortaliças no Brasil - 2000 - 2012. Disponível em http://www.cnph. embrapa.br/paginas/hortalicas_em_numeros/ producao_hortalicas.pdf. Acessado em 24 de junho de $\overline{2} 015$.

FILGUEIRA, FAR. 2008. Novo manual de olericultura: agrotecnologia moderna na produção e comercialização de hortaliças. Viçosa: UFV, 3 ed. 421p.

McCOLLUM, GO. 1971. Greening of carrot roots (Daucus carota L.): Estimates of heritability and correlation. Euphytica 20: 549-560.

RAMALHO, AR; ROCHA, RB; SOUZA, FF; TEIXEIRA, AL; VENEZIANO, W. 2011. Progresso genético com a seleção de clones de conilon no estado de Rondônia. In: SIMPÓSIO DE PESQUISA DOS CAFÉS DO BRASIL, 7. Anais... Araxá: SBPC (CD-ROM).

RESENDE, MDV. 2002a. Genética biométrica e estatística no melhoramento de plantas perenes. Brasília: Embrapa Informação Tecnológica. 975p.

RESENDE, MDV. 2002b. Software SelegenREML/BLUP. Curitiba: Embrapa Florestas. $67 \mathrm{p}$. 
RESENDE, MDV; DUARTE, JB. 2007. Precisão e controle de qualidade em experimentos de avaliação de cultivares. Pesquisa Agropecuária Tropical 37: 182-194.

SILVA, GO; CARVALHO, ADF; VIEIRA, JV. 2013. Caracterização e dissimilaridade entre populações de cenoura. Horticultura Brasileira 31: 52-57.

SILVA, GO; VIEIRA, JV. 2008. Componentes genéticos e fenotípicos para caracteres de importância agronômica em população de cenoura sob seleção recorrente. Horticultura Brasileira 26: 481-485.

SILVA, GO; VIEIRA, JV; VILLELA, MS. 2012. Dissimilaridade entre famílias e resposta correlacionada à seleção para caracteres de raiz de cenoura cultivada em dois sistemas de produção agroecológicos no Distrito Federal. Semina 33: 2115-2124.

SINGH, B; KUMAR, D; KUMAR, A; SINGH, G;
SINGH, G. 2002. Correlation studies in carrot (Daucus carota L.). Progressive Agriculture 2: 84-85.

VIEIRA, JV; BOITEUX, LS; ARAGÃO, FAS. 2001. Estimativas de parâmetros genéticos relativos ao comprimento de raízes de cenoura em populações derivadas da cultivar Alvorada. In: CONGRESSO BRASILEIRO DE OLERICULTURA, 41. Resumos... Brasília: SOB (CD-ROM). 